\section{BMJ Open} Ophthalmology

\title{
Persistent reduction of retinal
}

\section{microvascular vessel density in patients with moderate and severe COVID-19 disease}

Sandra Banderas García (D) , ${ }^{1}$ David Aragón, ${ }^{1}$ Brahim Azarfane, ${ }^{1}$ Fernando Trejo, ${ }^{1}$ Xavier Garrell-Salat, ${ }^{1}$ Adrián Sánchez-Montalvá, ${ }^{2}$ Susana Otero-Romero, ${ }^{3}$ Jose Garcia-Arumi, ${ }^{1,4}$ Miguel Angel Zapata ${ }^{1}$

\section{ABSTRACT}

Objective This study aims to analyse the possible recovery or worsening in retinal microvasculature after 8 months in a previously studied COVID-19 cohort.

Methods and analysis A cross-sectional casecontrol study and a prospective longitudinal cohort study. Participants were the subjects of our previous study who re-enrolled for a new examination including a fundus photograph (retinography), an optical coherence tomography (OCT) scan and an OCT angiography. COVID-19 diagnosed patients were divided into three groups: group 1: mild disease, asymptomatic/ paucisymptomatic subjects who received outpatient care; group 2: moderate disease and group 3: severe disease, both of which required hospital admission because of pneumonia. Statistical analyses were performed using SPSS software (V.23.0). Cross-sectional intergroup differences were analysed by means of analysis of variance for normally distributed variables and the KruskalWallis test for non-normally distributed ones. In reference to the prospective part of the study (intragroup differences, baseline with 8-month comparison), a paired t-test was used for normally distributed data and Wilcoxon signed ranks sum for non-normally distributed data.

Results The fovea-centered superficial and deep vascular densities were significantly diminished in severe cases compared with mild cases $(p=0.004 ; p=0.003$, respectively, for superficial and deep) and to controls $(p=0.014 ; p=0.010)$, also in moderate cases to mild group $(p=0.004 ; p=0.003)$ and to controls $(p=0.012 ; p=0.024)$. In the longitudinal study, no significant statistical differences were found between baseline and 8-month follow-up vessel density values.

Conclusion We demonstrated persistent reduction in the central vascular area over time in patients with moderate and severe COVID-19.

\section{INTRODUCTION}

Microvascular alterations in patients with COVID-19 have recently been described in several organs ${ }^{1}$ including the skin, lungs and retina. ${ }^{2}$ The SARS-CoV-2 was associated with organ dysfunction and generalised coagulopathy. ${ }^{3}$

\section{Key messages}

What is already known about this subject?

- The long-term consequences of COVID-19 on retinal vascularisation are still unknown. Reduced retinal vessel density in severe COVID-19 cases is described in the literature.

\section{What are the new findings?}

We demonstrated persistent reduction in the central vascular area over time in patients with moderate and severe COVID-19.

How might these results change the focus of research or clinical practice?

A close follow-up of patients with severe disease should be performed, in order to detect possible long-term systemic and ophthalmological sequelae.

COVID-19 is believed to bind the angiotensin-converting enzyme 2 (ACE2) receptor located on virtually all endothelia with high affinity. ${ }^{4}$ It activates the renin/ angiotensin system leading to a downregulation in ACE2 expression and increasing angiotensin II. Angiotensin II is known to be a potent vasoconstrictor and enhancer of the expression of tissue factor and plasminogen activator inhibitor leading to thrombosis. It also provokes complement activation via formation of reactive oxygen species and downregulation of C1 inhibitor, which increases vascular permeability and cytokine release, enhancing its thrombotic effect. ${ }^{5-7}$ SARS-CoV-2 infection induces a generalised microvascular thrombotic disorder and markedly elevated D-dimer, which has been associated with a worse prognosis of the disease. ${ }^{8}$

Retinal vascular changes in the form of decrease in radial peripapillary capillary plexus perfusion density, ${ }^{9}$ reduction in vessel density (VD) of foveal area and larger foveal 
avascular area $^{2} 10$ have been reported in patients with COVID-19 using optical coherence tomography angiography (OCT-A). Funduscopy exams have shown other features that are positively correlated with disease severity such as retinal venous diameter, presence of haemorrhages and cotton wool spots. ${ }^{11}$

In a previous study in which we assessed the state of retinal vascularisation via OCT-A in a cohort of 69 patients with COVID-19, we found lower central retina VD of the superficial plexus, in relation to the severity of the infection. ${ }^{10}$ OCT-A provides a safe and non-invasive diagnostic way of studying retinal vascular plexuses: superficial capillary plexus (SCP), deep capillary plexus (DCP) and choriocapillaris. ${ }^{12}$ OCT-A triton uses a central wavelength of $1.050 \mathrm{~nm}$ with $100.000 \mathrm{~A}$-scans per second to detect motion contrast and visualise blood flow in vivo. The OCT-A software uses a commercially available algorithm, OCTRA, which has been shown to provide highly sensitive detection of low blood flow in microvasculature, used in DRI OCT triton equipment. ${ }^{13}$

The long-term consequences of COVID-19 on retinal vascularisation are still unknown, as most of the available studies are cross-sectional. ${ }^{2}{ }^{10}$ Here, we provided an 8-month follow-up analysis of our previously studied cohort.

\section{MATERIALS AND METHODS}

Inclusion and selection of patients

We present a cross-sectional case-control study (8-month follow-up) and a prospective longitudinal cohort study (baseline and 8-month follow-up) performed at the Vall d'Hebron University Hospital (Barcelona, Spain). We included the participants of our previous study (JuneJuly 2020). ${ }^{10}$ Cases were defined as patients between 18 and 55 years of age with laboratory-confirmed SARSCoV-2 infection in the 3 months previous to enrolment in the study (June-July 2020). They were divided into: group 1: mild disease, asymptomatic/paucisymptomatic subjects who received outpatient care; group 2: moderate disease and group 3: severe disease, both of which required hospital admission because of pneumonia. Group 3 subjects developed acute respiratory distress syndrome with intensive care unit stay and interleukin 6 (IL-6) values in excess of $40 \mathrm{pg} / \mathrm{mL}$ at some point during hospitalisation. The control group consisted of healthy participants with negative serology for SARS-CoV-2 and any viral symptom in the 4 weeks prior to enrolment.

Exclusion criteria were consistent with the previous study: known prior ophthalmological diseases, myopia greater than -6 dioptres, diabetic retinopathy and active vascular diseases with retinopathy (multiple myeloma, hyperglobulinemia and malignant hypertension). Only one eye per patient is included in the analyses (the left one) in order to minimise the risk of bias.

All case and control subjects were asked to reconsent to participate in the extension phase of the study 8 months later (between 17 November 2020 and 29 January 2021). Data from the baseline examination was compared with the data obtained 8 months later. The control group was reassessed to confirm that they continued to meet the inclusion criteria, that is, no viral symptoms 4 weeks prior to the new assessment and negative serology. A flow chart depicts drop-outs (figure 1).

\section{Patient and public involvement statement}

Neither patients nor members of the public were involved in the design, conduct, reporting or dissemination plans of our research.

\section{Examinations performed}

A repetition of the same ocular examination from baseline was performed on all the subjects 8 months later: a $50^{\circ}$ colour photograph of the retina posterior pole (retinography), a macula-centred high-definition OCT (scan radial $12 \mathrm{~mm}$ ) and an automatically fovea-centred OCT-A $(4.5 \times 4.5 \mathrm{~mm})$ were performed. All three imaging techniques were obtained with the DRI OCT Triton Swept Source equipment (Topcon Corporation, Tokyo, Japan).
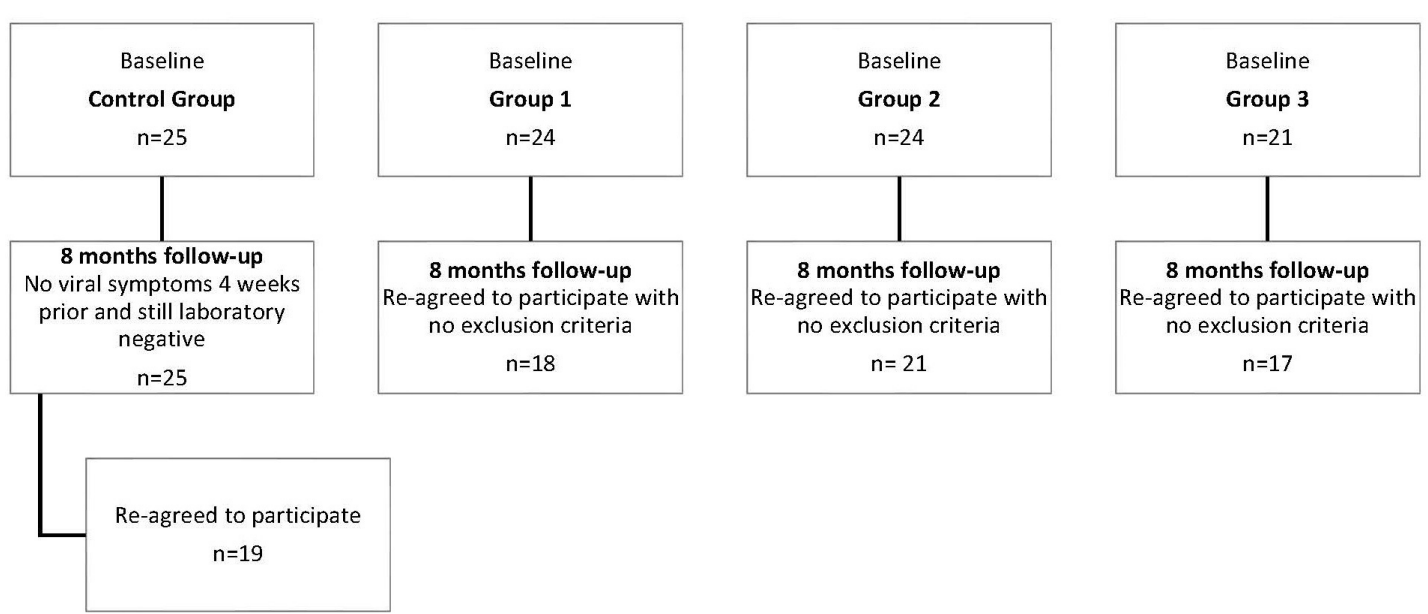

Figure 1 Flow chart of patient selection. Baseline accounts for 3-month analysis. The same participants of each group were approached and asked to take part in the follow-up analysis at 8 months. Subjects were once again assessed for inclusion and exclusion criteria. 


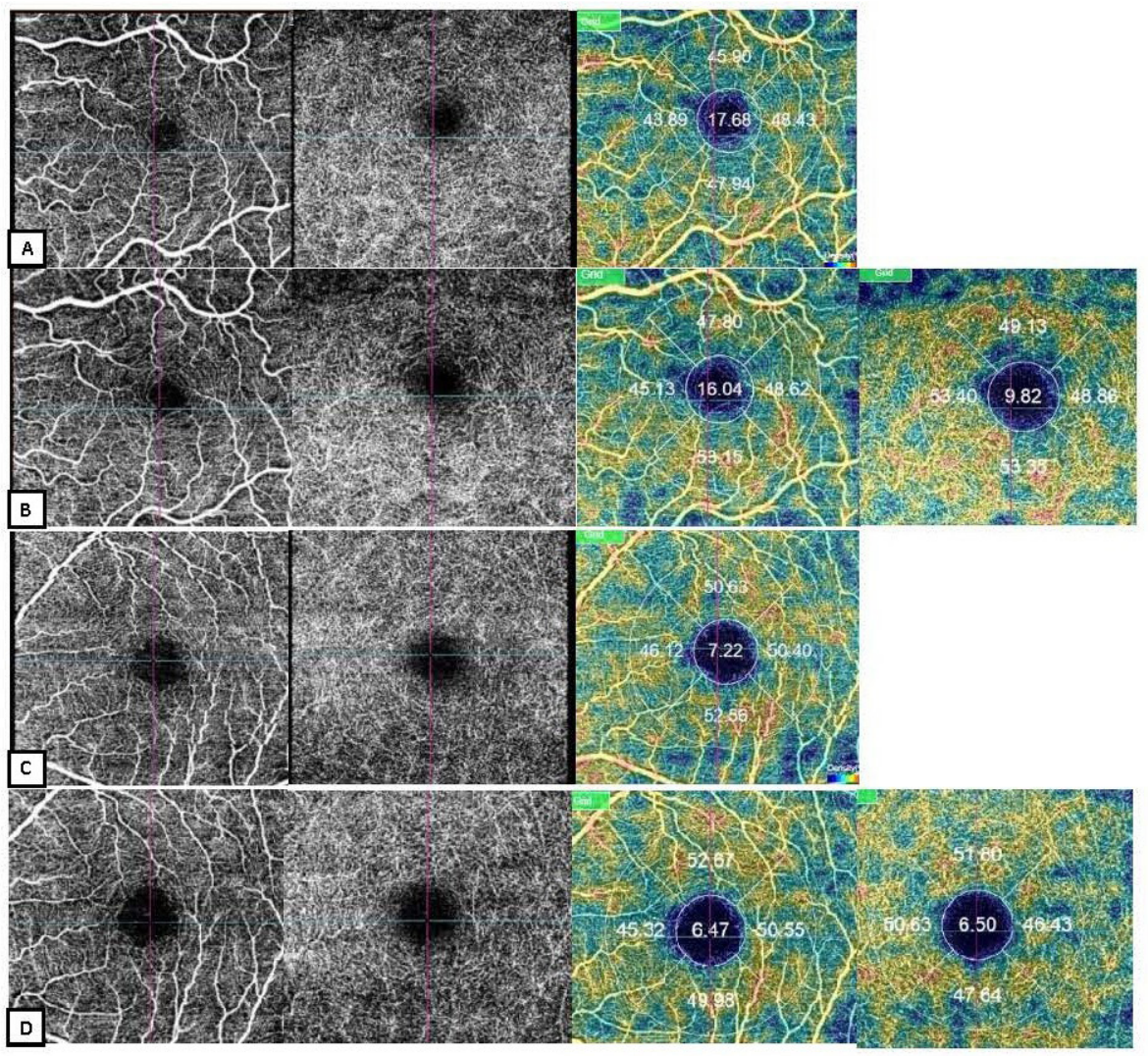

Figure 2 Example of the angiography by optical coherence tomography (OCT-A). The first images on the left correspond to superficial plexus, the second to deep plexus, the third to automated vessel density (VD) analysis of the superficial plexus and the fourth (if present) to the analysis of the VD in deep plexus. (A) Images correspond to the baseline data of a control group patient. (B) Images correspond to 8-month data of the same control group subject. (C) Images were obtained from a group three patient at baseline. (D) Images correspond to the same subject as in (C) but after 8 months. Note how in a macroscopic scale the tendency to a larger FAZ area and lower vascular density in the central area can be observed. No macroscopic abnormalities in the morphology of FAZ are noted: no notches, avascular areas or vessel irregularities. FAZ, foveal avascular zone.

Retinography images and radial OCT sections were analysed by two different ophthalmologists (SBG and DA). A third ophthalmologist carried out a double evaluation of the images (MAZ). A search for any abnormality such as haemorrhages, cotton wool spots or OCT layer hyperreflectivities was carried out.

In contrast to our previous study, we gathered data from automatic segmentation from both superficial capillary plexus and deep capillary plexus from the macular region. Superficial layer VD was automatically segmented: from the internal limiting membrane (ILM) at a depth of 2.6 $\mathrm{mm}$ to the inner plexiform layer (IPL) / inner nuclear layer (INL) at a depth of $15.6 \mu \mathrm{m}$. IPL/ INL at $15.6 \mu \mathrm{m}$ to INL/outer plexiform layer at $70.2 \mu \mathrm{m}$ automatically encompasses the deep layer VD. The specified software calculated VD, and data were collected from superior, inferior, nasal, temporal and central areas. All captures with a signal strength index of less than 40, incorrect segmentation or motion artefacts were excluded. Figure 2 shows an example of the images obtained.

The area of the foveal avascular zone (FAZ) in the superficial capillary plexus was analysed by means of manual delineation of randomly numbered images with Image J Software (National Institutes of Health) by three different blinded observers (SBG, DAR and MAZ). The surface area was measured in square pixels and was converted to square millimetres using the formula given by the software (scale setting): delineated area $\left(\mathrm{mm}^{2}\right)=$ delineated area $\left(\right.$ pixel $\left.^{2}\right) /$ total surface area $\left(\right.$ pixel $\left.^{2}\right) *$ total surface area $\left(\mathrm{mm}^{2}\right)$. No editing of the image was performed to increase contrast or change colours prior to manual delineation.

\section{Statistical analysis}

Statistical analyses were performed using SPSS (V.23.0) software. Normal distribution of the variables was checked using the Kolmogorov-Smirnov test. In the first part of the study, cross-sectional intergroup differences were analysed (8-month time). Quantitative variables that followed a normal distribution were studied with an analysis of variance (ANOVA) using Bonferroni correction. A Kruskal-Wallis test was performed to compare quantitative variables not normally distributed. Qualitative variables were examined using the $\chi^{2}$ test. 
Table 1 Demographic features of study population

\begin{tabular}{|c|c|c|c|c|c|c|}
\hline & & Control group & Group 1: mild disease & $\begin{array}{l}\text { Group 2: moderate } \\
\text { disease }\end{array}$ & $\begin{array}{l}\text { Group 3: severe } \\
\text { disease }\end{array}$ & $\begin{array}{l}\text { Significance } \\
\text { among all groups }\end{array}$ \\
\hline $\begin{array}{l}\text { Months from PCR } \\
\text { (mean, SD) }\end{array}$ & & - & - & $8.20(0.62)$ & $8.74(0.68)$ & \\
\hline \multirow[t]{2}{*}{ Gender (n, \%) } & Male & $8(42.10)$ & $6(33.33)$ & $9(42.85)$ & $9(52.94)$ & $0.711^{*}$ \\
\hline & Female & $11(57.89)$ & $12(66.66)$ & $12(57.14)$ & $8(47.05)$ & \\
\hline Age (years, SD) & & $38,79(8,15)$ & $40,61(11,04)$ & $43,29(8,49)$ & $46,00(5,75)$ & $0.078^{+}$ \\
\hline \multirow[t]{3}{*}{ Race (n) } & Caucasian & 19 & 17 & 15 & 9 & $0.008^{\star}$ \\
\hline & Latin & 0 & 1 & 6 & 7 & \\
\hline & Other & 0 & 0 & 0 & 1 & \\
\hline \multirow[t]{2}{*}{ Diabetes (n) } & No & 19 & 18 & 20 & 15 & $0.236^{*}$ \\
\hline & Yes & 0 & 0 & 1 & 2 & \\
\hline \multirow[t]{2}{*}{ Smoker (n) } & No & 16 & 15 & 21 & 15 & $0.292^{*}$ \\
\hline & Yes & 3 & 3 & 0 & 2 & \\
\hline
\end{tabular}

Significant values shown in bold.

${ }^{*} X^{2}$ test.

†ANOVA test.

ANOVA, analysis of variance.

In reference to the prospective part of the study (intragroup differences), a paired t-test was used for normally distributed data in order to compare baseline and 8-month changes in the VD mean for superficial plexus as well as for the FAZ mean area. A Wilcoxon signed ranks sum test was used for not normally distributed VD means.

Significance was fixed at $\mathrm{p}$ values below 0.05 .

\section{RESULTS}

Study population

We included a total of 75 patients from our previous study $^{9}$ who reagreed to participate with no exclusion criteria (figure 1). Control group was formed by 19 subjects. Among patients with laboratory-confirmed SARS-CoV-2 infection, group 1 included 18 participants, group 2 included 21 and group 3 included 17. Mean duration from PCR-confirmed diagnosis to ophthalmological examination time was 8.74 months (SD 0.68) for group 2 and 8.20 months (SD 0.62) for group 3. As in the previous study, there were no statistically significant differences between groups in terms of age, gender, smoking or diabetes record (table 1). The mean age was lower in the control group and group 1 than in groups 2 and 3, with no statistical significance. In reference to ethnicity, there was statistical difference: a predominance of Caucasian origin in all groups with a statistically significant greater presence of Latin origin in groups 2 and 3 $(\mathrm{p}=0.008)$.

\section{Fundoscopic and structural OCT findings}

No new abnormalities in previously healthy colour fundus images and structural OCT sections were found. No abnormalities attributable to SARS-CoV-2 were found. In line with our previous findings, there were two subjects who presented asymptomatic small pigment epithelial detachments and one group 2 patient with a small haemorrhage suggestive of a Valsalva manoeuvre (size of approximately $100 \mu \mathrm{m}$, round and well-circumscribed under ILM in the premacular area).

\section{OCT-A and VD}

\section{Cross-sectional results}

At macroscopic scale, no abnormalities such as neovascularisation, ischaemic areas, vascular dilatation or abnormal organisation of vessels were detected after careful consideration of OCT-A images by three observers (SBG, DA and MAZ) either in control or in case groups. The FAZ tended to have a larger area in severe cases, with a statistically significant difference in means among groups $(p<0.001$, (online supplemental figure 2$)$ and table 2): control group versus group $2(\mathrm{p}<0.001)$; control group versus group $3(\mathrm{p}=0.001)$; group 1 versus group 2 $(p<0.001)$; and group 1 versus group $3(p<0.001)$. The mean superficial and deep VDs in control group for the central area were 16.14 and 15.49 (SD 3.40; 4.61), in group 1 , they were 17.41 and 15.78 (SD $4.07 ; 4.06$ ), in group 2, they were 13.41 and 12.43 (SD $4.79 ; 5.38$ ) and in group 3, they were 12.96 and 11.38 (SD 3.56; 3.93) (online supplemental figures 2 and 3 ) and table 2). These data were non-normally distributed. After analysis with Kruskal-Wallis, a statistically significant difference of central VD means among groups was found: $p=0.002$ for both global comparison of all groups for superficial and deep. Superficial and deep central VD means in control group and in group 1 were higher than in group 2 and group 3. In a Mann-Whitney $U$ test (the first $p$ value represents superficial and the second represents deep), statistical differences were found in the control group versus group 2 ( $\mathrm{p}=0.012 ; \mathrm{p}=0.024)$, and the control group versus group $3(\mathrm{p}=0.014 ; \mathrm{p}=0.010)$, group 1 versus group $2(\mathrm{p}=0.004 ; \mathrm{p}=0.003)$ and group 1 versus group 3 $(\mathrm{p}=0.005 ; \mathrm{p}=0.003)$. 
Table 2 Vascular density values at the 8-month follow-up and other characteristics within groups

\begin{tabular}{|c|c|c|c|c|c|c|}
\hline & & Control group & $\begin{array}{l}\text { Group 1: mild } \\
\text { disease }\end{array}$ & $\begin{array}{l}\text { Group 2: moderate } \\
\text { disease }\end{array}$ & $\begin{array}{l}\text { Group 3: severe } \\
\text { disease }\end{array}$ & $\begin{array}{l}\text { Significance among } \\
\text { all groups }\end{array}$ \\
\hline \multirow[t]{2}{*}{ Superficial central VD } & Mean & 16.1432 & 17.416 & 13.411 & 12.968 & $0.002^{*}$ \\
\hline & SD & 3.405 & 4.079 & 4.793 & 3.566 & \\
\hline \multirow[t]{2}{*}{ Superficial inferior VD } & Mean & 50.368 & 50.125 & 52.980 & 50.464 & $0.761^{*}$ \\
\hline & SD & 2.712 & 3.321 & 8.293 & 2.483 & \\
\hline \multirow[t]{2}{*}{ Superficial superior VD } & Mean & 49.995 & 49.013 & 50.128 & 50.141 & $0.391 \dagger$ \\
\hline & SD & 2.406 & 2.053 & 2.376 & 2.666 & \\
\hline \multirow[t]{2}{*}{ Superficial nasal VD } & Mean & 43.373 & 42.716 & 44.530 & 44.340 & $0.163 \dagger$ \\
\hline & SD & 2.302 & 3.496 & 2.694 & 2.485 & \\
\hline \multirow{2}{*}{$\begin{array}{l}\text { Superficial } \\
\text { temporal VD }\end{array}$} & Mean & 47.711 & 46.015 & 49.925 & 48.271 & $<0.001 \dagger$ \\
\hline & SD & 2.369 & 3.461 & 2.602 & 2.307 & \\
\hline \multirow[t]{2}{*}{ Image quality } & Mean & 63.42 & 63.44 & 61.950 & 64.120 & $0.452 \dagger$ \\
\hline & SD & 3.220 & 5.044 & 5.162 & 3.100 & \\
\hline \multirow[t]{2}{*}{ FAZ area } & Mean & 0.223 & 0.210 & 0.411 & 0.343 & $<0.001 \dagger$ \\
\hline & SD & 0.150 & 0.017 & 0.022 & 0.026 & \\
\hline \multirow[t]{2}{*}{ Deep central VD } & Mean & 15.495 & 15.782 & 12.430 & 11.388 & $0.002^{*}$ \\
\hline & SD & 4.613 & 4.068 & 5.382 & 3.933 & \\
\hline \multirow[t]{2}{*}{ Deep inferior VD } & Mean & 51.507 & 53.223 & 53.324 & 52.645 & $0.7347^{*}$ \\
\hline & SD & 5.327 & 3.974 & 3.809 & 3.218 & \\
\hline \multirow[t]{2}{*}{ Deep superior VD } & Mean & 51.066 & 50.996 & 52.466 & 51.361 & $0.484 \dagger$ \\
\hline & SD & 3.606 & 3.167 & 3.451 & 3.175 & \\
\hline \multirow[t]{2}{*}{ Deep nasal VD } & Mean & 49.497 & 46.551 & 50.707 & 49.419 & $0.010 \dagger$ \\
\hline & SD & 3.693 & 3.021 & 4.499 & 3.650 & \\
\hline \multirow[t]{2}{*}{ Deep temporal VD } & Mean & 48.034 & 48.430 & 50.092 & 47.708 & $0.043^{*}$ \\
\hline & SD & 2.898 & 2.893 & 3.027 & 2.769 & \\
\hline
\end{tabular}

Significant values shown in bold.

*H Kruskal-Wallis.

†ANOVA test.

ANOVA, analysis of variance; FAZ, foveal avascular zone; VD, vessel density.

Normally distributed data of superficial temporal and nasal deep VD were analysed with ANOVA, and a statistical difference was noted $(\mathrm{p}=0.002 ; \mathrm{p}=0.010)$. After Bonferroni correction for multiple measurements, a statistical difference was found only between group 1 and group $2(\mathrm{p}<0.001, \mathrm{p}=0.006)$ with no differences among other groups. Non-normally distributed data from temporal deep VD was analysed using Kruskal-Wallis, with a significant statistical difference in means among groups $(\mathrm{p}=0.043)$ which, after a Mann Whitney U test, was found to be between the control group and group 2 $(\mathrm{p}=0.021)$ and between group 2 and group $3(\mathrm{p}=0.011)$.

No other statistically significant results were found. Table 2 shows a summary of all comparisons.

VD differences between male and female within every group were also examined (online supplemental table) as general tendency to lower values in female data were found. The following statistically significant different means were found: superficial central VD at baseline for group 1 was higher in women than men $(p=0.034)$; superficial inferior VD at baseline for group 2 was higher in men than women $(p=0.009)$; deep central VD for group 2 at 8-month follow-up was higher in men than women $(\mathrm{p}=0.039)$ also for group 3 at 8-month follow-up $(\mathrm{p}=0.031)$; and deep inferior VD for group 2 at 8-month follow-up was higher in women group than men group $(\mathrm{p}=0.018)$.

\section{Prospective results}

A paired t-test was performed for normally distributed data and a Wilcoxon signed rank test for non-normally distributed variables (table 3). Comparison of the VD means of every area of the superficial plexus between baseline and its value at the 8 month follow-up was made. FAZ areas are also included in the prospective analysis. No statistically significant differences were found (online supplemental figure 2).

\section{DISCUSSION}

The main finding of this study is lower central retinal VD in superficial and deep plexuses in patients who have suffered from moderate and severe COVID-19 pneumonia. This is the first study to provide evidence of the persistence of these findings after 8-month follow-up. 


\begin{tabular}{|c|c|c|c|c|c|}
\hline SCP VD & Global & Group 1 & Group 2 & Group 3 & Control group \\
\hline Central & $p=0.143^{*}$ & $p=0.102^{*}$ & $\mathrm{p}=0.835^{\star}$ & $\mathrm{p}=0.647^{*}$ & $\mathrm{p}=0.147^{*}$ \\
\hline Inferior & $p=0.065^{\star}$ & $p=0.215^{\star}$ & $\mathrm{p}=0.073^{*}$ & $p=0.369^{\star}$ & $p=0.094^{*}$ \\
\hline Superior & $p=0.105 \dagger$ & $\mathrm{p}=0.756^{*}$ & $p=0.230$ * & $p=0.616^{*}$ & $\mathrm{p}=0.313$ * \\
\hline Nasal & $p=0.714^{\star}$ & $\mathrm{p}=0.679^{\star}$ & $\mathrm{p}=0.375^{\star}$ & $\mathrm{p}=0.557^{*}$ & $\mathrm{p}=0.117^{*}$ \\
\hline Temporal & $\mathrm{p}=0.612$ * & $\mathrm{p}=0.619$ * & $\mathrm{p}=0.58$ * & $\mathrm{p}=0.811^{*}$ & $p=0.108^{*}$ \\
\hline FAZ area & $p=0.181 \dagger$ & $p=0.330 \dagger$ & $p=0.141 \dagger$ & $p=0.453 \dagger$ & $p=0.082 \dagger$ \\
\hline
\end{tabular}

Significant values shown in bold.

Superficial plexus VD mean comparison at baseline and at 8-month examination.

*Wilcoxon signed rank test.

†Paired t-test.

FAZ, foveal avascular zone; SCP, superficial capillary plexus; VD, vessel density.

SARS-CoV-2 virus is suspected to cause a type of microvascular angiopathy ${ }^{14}$ consisting of acute endothelial dysfunction mediated by proinflammatory cytokines such as tumour necrosis factor alpha or IL-6 that lead to an enhanced risk of microvascular thrombosis and eventually multiorgan dysfunction. Direct injury as a result of the infection via this process has been reported in postmortem studies in organs such as brain,,$^{15}$ liver $^{16}$ and kidney. ${ }^{17}$ This increase in micro thrombosis could lead to diminished vascular density in affected organs such as the vascular plexuses of the retina.

The severe and moderate infection groups in our study showed signs of respiratory distress and increased IL-6 in the latter group, which are believed to be signs of an underlying thrombotic microangiopathy. ${ }^{18}$ IL-6 increase is a sign of inflammation in SARS-CoV-2 disease linked to an unfavourable outcome of the disease and the best predictor for the requirement of invasive mechanical ventilation. ${ }^{19}$ IL- 6 correlates with macrophage activation in severe COVID-19 cases $^{20}$ and seems to have a role in microvascular angiopathy by inhibition of ADMTS-13 activity, raising levels of fibrinogen, plasminogen inhibitor- 1 and $\mathrm{C}$ reactive protein. ${ }^{21}{ }^{22}$ In our first study, ${ }^{10}$ we demonstrated the existence of a reduction in the central VD of the superficial plexus via OCT-A and a tendency to a larger FAZ area. Other groups have ratified our findings with similar results. ${ }^{2324}$ There may be three reasons for this: one, ACE2 expressed in the endothelium of the retina ${ }^{20}$ with direct effect; two, induced-endothelitis; and three, metabolic changes by serum IL-6 leading to disturbances of the blood retina barrier and dysfunction of vessels. $^{25}$

In the present study, reduction of vascular density remains stable after 8 months (online supplemental figure 2). This is the most important finding of the present study, that is, the persistence of significant lower VDs in severe and moderate disease. A comparison with the control group to evaluate the impact of ageing was undertaken, which proves the consistency of the persistently reduced central SCP, DCP and enlarged FAZ area, and this correlates with the results of other groups at 6 months. ${ }^{23}$ As a tendency to a negative correlation was found regarding sex and central VD in our previous study ${ }^{10}$ we decided to examine possible differences in VD data between male and female groups at baseline and at follow-up (online supplemental material). GuemesVillahoz et $a t^{23}$ suggested that women could undergo either slower recovery or progressive worsening of retinal VD and questioned whether this might have any relationship to major persistence of neurological symptoms after the illness in the female population. In our study, VDs of all areas in the female group, although generally lower than in the male group, were mostly no different. We found no other reports in the literature with evidence supporting the possibility that women would be at higher risk of COVID-19 vascular-related events. Further research in this direction is planned.

The long-term consequences of COVID-19 in the retina have not been examined. As far as we know, no clinical or fundoscopic macroscopic abnormalities were discovered at follow-up, such as we could expect as a consequence of the reduced VD. We found only one isolated case report of persistent cotton wool spots on fundus examination at 6 months. ${ }^{23}$ For the moment, none of our patients presented any clinical consequences of the microvascular abnormalities evidenced herein. Some studies have tried to relate retinal fibre nerve layer and ganglion cell layer thicknesses with decreases in VD, but no structural correlations have been found. ${ }^{24}$ It is still not known whether vasculature structures of the retinal plexuses are more vulnerable to thrombotic events than other body plexuses, as these abnormalities seem to remain clinically silent. We believe long-term follow-up is needed to assess future possible ischaemic/neovascular diseases of the retina, especially in patients who have suffered from severe COVID-19.

If persistent microvascular changes are found in the retina beyond 8 months, it may be presumed that other organs and their plexuses may have sustained longterm damage. Current studies focus their attention on 'persistent COVID-19,26 and reveal frequencies of up to $72 \%$ of concentration ability difficulties, $68 \%$ of insomnia, $64 \%$ of memory impairment, $75 \%$ of fatigue, $55 \%$ of tachycardia and $63 \%$ of nonproductive cough, 
among other symptoms. There is currently a controversy regarding the relationship between psychological and functional impairment, systemic consequences and initial severity. Some studies, such as that of Huang $e t a l^{27}$ did find an association between acute COVID-19 disease severity, persistence of symptoms such as fatigue, weakness, anxiety, impaired pulmonary diffusion capacities and chest imaging abnormalities. Further studies are needed to assess whether recovery symptoms in critical illness patients are comparable with those typically seen in acute respiratory distress syndrome survivors, ${ }^{28}$ or whether persistent poor health after COVID-19 is finally not associated with respiratory complications. ${ }^{29}$ How perfusion reduction during acute SARS-CoV-2 infection leads to long-term sequelae of the virus in several organs and how this correlates to later symptoms is currently being examined in research papers: pancreatic islets, ${ }^{30}$ heart, ${ }^{31}$ brain $^{32}$ or kidney. ${ }^{26}$

If this were the case, VD of the retina measured by OCT-A would be of use as a marker of widespread organ injury in post-COVID-19 patients. Hekimsoy et $a l^{33}$ have already established a negative correlation between retinal perfusion and idiopathic pulmonary arterial hypertension, a pathology that has been studied in recent times in the context of COVID- $19^{34}$ and that results in a higher fatality rate when SARS-CoV-2 infection occurs. Further studies to correlate systemic signs/symptoms are necessary to elucidate this question. Interestingly, perfusion studies with tomography angiography in the lungs and kidneys of COVID-19 patients showed perfusion deficits suggestive of microvascular occlusion with no detectable major dysfunction, similar to our findings. ${ }^{35}$

We acknowledge a series of limitations in our study. First, the small sample size of the case cohort, as a consequence of the prospective nature of the study, with reduced number of patients willing to attend a second ophthalmic examination, lower surveillance rates in moderate and severe disease groups, and the study of only one eye per patient. Second, the absence of comorbidities in our population might need to be taken into account when assessing comparability to our studies. Cotton wool spots and retinal haemorrhages are reported in patients with COVID-19 who commonly also have other pre-existing comorbid conditions. ${ }^{36}$ We believe that the lack of comorbidities might be beneficial for measuring the real impact of the SARS-CoV-2 infection on VD, since the presence of multiple pathologies might affect its values. Third, no retinal periphery studies have been performed, and we lack any information regarding functional translation of our changes, for example, via electroretinography or microperimetry, which would be of use to state with confidence that there are no clinical consequences. Fourth, a longer follow-up than 8 months should be carried out. Prospective studies on larger cohorts will be needed for follow-up of retinal microvascular abnormalities in post-COVID-19 patients, especially in moderate and severe cases, to detect progression, reversibility or vascular consequences.
In conclusion, this is the first study to find persistently reduced VDs in the retina 8 months after COVID-19 infection. We demonstrate persistent tendency towards a larger FAZ area and reduction in the central area of the superficial and deep plexuses, with correlation to disease severity. Therefore, we believe close follow-up of patients with severe disease should be performed, in order to detect possible long-term systemic and ophthalmological disease sequelae.

Acknowledgements We would like to acknowledge the contribution of the Surgery Department of the Autonomous University of Barcelona (UAB Departament de Cirurgia i Ciències Morfològiques).

Contributors MAZ and SBG made a substantial contribution to the present work in the design of the study, acquisition, analysis and interpretation of data, manuscript drafting and approval of the version of the manuscript to be published. AS-M and SO-R contributed to acquisition of data, conception and design of the study, critical revision for important intellectual content and approval of the version to be published. DA, BA, XG-S and FT participated in the data acquisition, critical revision for important intellectual content and approval of the present version of the manuscript. JG-A's contribution to the present work included conception and design of the study, critical revision for important intellectual content and approval of the present document. SBG is the guarantor and accepts full responsibility for the work, conduct of the study, had access to the data, and controlled the decision to publish. All the authors hereby mentioned meet all four ICMJE criteria for authorship and are accountable for all aspects of the work regarding its accuracy and integrity.

Funding The authors have not declared a specific grant for this research from any funding agency in the public, commercial or not-for-profit sectors.

Competing interests None declared.

Patient consent for publication Consent obtained directly from patient(s)

Ethics approval The study was approved by the Vall d'Hebron University Hospital ethical committee under the number PR (AG) 337/2020, and all enrolled subjects signed an informed consent statement. Participants gave informed consent to participate in the study before taking part.

Provenance and peer review Not commissioned; externally peer reviewed.

Data availability statement Data are available on reasonable request. All data relevant to the study are included in the article or uploaded as supplementary information. All data relevant to the study are included in the article or uploaded as supplementary information, but additional data are available on reasonable request.

Supplemental material This content has been supplied by the author(s). It has not been vetted by BMJ Publishing Group Limited (BMJ) and may not have been peer-reviewed. Any opinions or recommendations discussed are solely those of the author(s) and are not endorsed by BMJ. BMJ disclaims all liability and responsibility arising from any reliance placed on the content. Where the content includes any translated material, BMJ does not warrant the accuracy and reliability of the translations (including but not limited to local regulations, clinical guidelines, terminology, drug names and drug dosages), and is not responsible for any error and/or omissions arising from translation and adaptation or otherwise.

Open access This is an open access article distributed in accordance with the Creative Commons Attribution Non Commercial (CC BY-NC 4.0) license, which permits others to distribute, remix, adapt, build upon this work non-commercially, and license their derivative works on different terms, provided the original work is properly cited, appropriate credit is given, any changes made indicated, and the use is non-commercial. See: http://creativecommons.org/licenses/by-nc/4.0/.

ORCID iD

Sandra Banderas García http://orcid.org/0000-0002-3641-3806

\section{REFERENCES}

1 Magro C, Mulvey JJ, Berlin D, et al. Complement associated microvascular injury and thrombosis in the pathogenesis of severe COVID-19 infection: a report of five cases. Transl Res 2020;220:1-13. 
2 González-Zamora J, Bilbao-Malavé V, Gándara E, et al. Retinal microvascular impairment in COVID-19 bilateral pneumonia assessed by optical coherence tomography angiography. Biomedicines 2021;9:247.

3 Tang N, Li D, Wang X, et al. Abnormal coagulation parameters are associated with poor prognosis in patients with novel coronavirus pneumonia. J Thromb Haemost 2020;18:844-7.

4 Sparks MA, Crowley SD, Gurley SB, et al. Classical renin-angiotensin system in kidney physiology. Compr Physiol 2014;4:1201-28.

5 Shagdarsuren E, Wellner M, Braesen J-H, et al. Complement activation in angiotensin II-induced organ damage. Circ Res 2005;97:716-24.

6 Forrester SJ, Booz GW, Sigmund CD, et al. Angiotensin II signal transduction: an update on mechanisms of physiology and pathophysiology. Physiol Rev 2018;98:1627-738.

7 Bekassy Z, Lopatko I, Bader M. Crosstalk between the reninangiotensin, complement and kallikrein-kinin systems in inflammation. Nat Rev Immunol 2021:1-18.

8 Zhou F, Yu T, Du R, et al. Clinical course and risk factors for mortality of adult inpatients with COVID-19 in Wuhan, China: a retrospective cohort study. Lancet 2020;395:1054-62.

9 Savastano A, Crincoli E, Savastano MC, et al. Peripapillary retinal vascular involvement in early Post-COVID-19 patients. J Clin Med 2020;9:2895

10 Zapata Miguel Ángel, Banderas García S, Sánchez-Moltalvá A, et al. Retinal microvascular abnormalities in patients after COVID-19 depending on disease severity. $\mathrm{Br} J$ Ophthalmol 2020;317953. doi:10.1136/bjophthalmol-2020-317953. [Epub ahead of print: 16 Dec 2020].

11 Invernizzi A, Torre A, Parrulli S, et al. Retinal findings in patients with COVID-19: results from the SERPICO-19 study. EClinicalMedicine 2020;27:100550.

12 Spaide RF, Fujimoto JG, Waheed NK, et al. Optical coherence tomography angiography. Prog Retin Eye Res 2018;64:1-55.

13 Moussa M, Leila M, Khalid H. Imaging choroidal neovascular membrane using en face swept-source optical coherence tomography angiography. Clin Ophthalmol 2017;11:1859-69.

14 Iba T, Connors JM, Levy JH. The coagulopathy, endotheliopathy, and vasculitis of COVID-19. Inflamm Res 2020;69:1181-9.

15 Younger DS. Postmortem neuropathology in COVID-19. Brain Pathol 2021;31:385-6.

16 Zhao CL, Rapkiewicz A, Maghsoodi-Deerwester M, et al. Pathological findings in the postmortem liver of patients with coronavirus disease 2019 (COVID-19). Hum Pathol 2021;109:59-68.

17 Varga Z, Flammer AJ, Steiger P, et al. Endothelial cell infection and endotheliitis in COVID-19. Lancet 2020;395:1417-8.

18 Dolhnikoff M, Duarte-Neto AN, de Almeida Monteiro RA, et al. Pathological evidence of pulmonary thrombotic phenomena in severe COVID-19. J Thromb Haemost 2020;18:1517-9.

19 Aziz M, Fatima R, Assaly R. Elevated interleukin-6 and severe COVID-19: a meta-analysis. J Med Virol 2020;92:2283-5.
20 McGonagle D, Sharif K, O'Regan A, et al. The role of cytokines including interleukin-6 in COVID-19 induced pneumonia and macrophage activation syndrome-like disease. Autoimmun Rev 2020;19:102537.

21 Libby P, Simon DI. Inflammation and thrombosis: the clot thickens. Circulation 2001;103:1718-20.

22 Lee DD, Schwarz MA. Cell-Cell communication breakdown and endothelial dysfunction. Crit Care Clin 2020;36:189-200.

23 Guemes-Villahoz N, Burgos-Blasco B, Vidal-Villegas B, et al. Reduced retinal vessel density in COVID-19 patients and elevated D-dimer levels during the acute phase of the infection. Med Clin 2021;156:541-6.

24 Cennamo G, Reibaldi M, Montorio D, et al. Optical coherence tomography angiography features in Post-COVID-19 pneumonia patients: a pilot study. Am J Ophthalmol 2021;227:182-90.

25 Teuwen L-A, Geldhof V, Pasut A, et al. COVID-19: the vasculature unleashed. Nat Rev Immunol 2020;20:389-91.

26 Rando HM, Bennett TD, Byrd JB, et al. Challenges in defining long COVID: striking differences across literature, electronic health records, and patient-reported information. medRxiv 2021. doi:10.110 1/2021.03.20.21253896. [Epub ahead of print: 26 Mar 2021].

27 Huang C, Huang L, Wang Y, et al. 6-Month consequences of COVID-19 in patients discharged from Hospital: a cohort study. Lancet 2021;397:220-32.

28 Parker AJ, Humbir A, Tiwary P, et al. Recovery after critical illness in COVID-19 ICU survivors. Br J Anaesth 2021;126:e217-9.

29 Townsend L, Dowds J, O'Brien K, et al. Persistent poor health after COVID-19 is not associated with respiratory complications or initial disease severity. Ann Am Thorac Soc 2021;18:997-1003.

30 Hayden MR. An immediate and long-term complication of COVID-19 may be type 2 diabetes mellitus: the central role of $\beta$-cell dysfunction, apoptosis and exploration of possible mechanisms. Cells 2020;9:2475.

31 Liu J, Deswal A, Khalid U. COVID-19 myocarditis and long-term heart failure sequelae. Curr Opin Cardiol 2021;36:234-40.

32 Guedj E, Campion JY, Dudouet P, et al. ${ }^{18} \mathrm{~F}-\mathrm{FDG}$ brain PET hypometabolism in patients with long COVID. Eur J Nucl Med Mol Imaging 2021;48:2823-33.

33 Hekimsoy V, Kılınç Hekimsoy H, Șekeroğlu MA, et al. The relationship between retinal microcirculation and right heart catheterization and echocardiography findings in patients with idiopathic pulmonary arterial hypertension. Microcirculation 2021;28:e12704.

34 Sulica R, Cefali F, Motschwiller C, et al. COVID-19 in pulmonary artery hypertension (PAH) patients: observations from a large PAH center in New York City. Diagnostics 2021;11:128.

35 Idilman IS, Telli Dizman G, Ardali Duzgun S, et al. Lung and kidney perfusion deficits diagnosed by dual-energy computed tomography in patients with COVID-19-related systemic microangiopathy. Eur Radiol 2021;31:1090-9.

36 Sim R, Cheung G, Ting D. Retinal microvascular signs in COVID-19. Br J Ophthalmol 2021. 